\title{
AS PRÁTICAS DE AVALIACÃO DE DOCUMENTOS NOS ARQUIVOS FEDERAIS DA ALEMANHA
}

\author{
APPRAISAL PRACTICES IN GERMANY'S FEDERAL ARCHIVES
}

Maria Juliana Nunes da Silva ${ }^{1}$

Ivana Denise Parrela

\begin{abstract}
RESUMO
Diversas discussões, de ordem teórica, prática e metodológica, vêm sendo produzidas sobre avaliação de documentos em diferentes países. A Alemanha, que tem vasta tradição na área de Arquivos, contribui de maneira notável em matéria de avaliação, embora a literatura que produz em outras línguas sobre sua experiência seja reduzida. Este trabalho tem por objetivo discorrer sobre a avaliação de documentos no âmbito dos Arquivos Federais da Alemanha (Bundesarchiv). Justifica-se por ampliar as informações arquivísticas de um país com uma rica produção sobre arquivos, porém pouco difundida fora dele. A pesquisa faz parte de um estudo de doutorado em andamento. Caracteriza por ser qualitativa e de caráter exploratório. A metodologia utilizada contemplou a pesquisa bibliográfica e a entrevista estruturada foi usada como técnica de coleta de dados. Constatou-se a existência de diferentes abordagens nas esferas da administração pública, 0 que confirma que estudar a função avaliação não é uma tarefa simples de se pensar, muito menos de se praticar, mas que é fundamental conhecer e debater sobre outras formas de executá-la tanto em diferentes níveis estruturais/organizacionais como em função dos diferentes contextos históricos.
\end{abstract}

Palavras-chave: Avaliação de documentos. Arquivos Federais. Alemanha. Arquivologia. Gestão de documentos.

\begin{abstract}
Several discussions, of theoretical, practical and methodological order, have been produced on document appraisal in different countries. Germany, which has a long tradition in the area of Archives, makes a notable contribution to appraisal, although the literature it produces in other languages about its experience is limited. This work aims to discuss the appraisal of documents within the Federal Archives of Germany (Bundesarchiv). It is justified by expanding the archival information of a country with a rich production on archives, but little disseminated outside it. The research is part of an ongoing doctoral study. It is characterized by being qualitative and exploratory. The methodology used included the bibliographic research and the structured interview was used as a data collection technique. It was found that there are different approaches in the spheres of public administration, which confirms that studying the appraisal function is not a simple task to think about, much less to practice, but that it is essential to know and debate about other ways of executing it. It both at different structural / organizational levels and as a function of different historical contexts.
\end{abstract}

Keywords: Appraisal. Federal Archives. Germany. Archival Science. Records managements.

Artigo submetido em 25/05/2020 e aceito para publicação em 28/05/2020

1 Doutoranda no Programa de Pós-Graduação em Ciência da Informação da Universidade Federal de Minas Gerais, Brasil. ORCID: https://orcid.org/0000-0002-6397-0632. E-mail: mariajuliana@ufmg.br

2 Professora associada do Departamento de Teoria e Gestão da Informação. Escola de Ciência da Informação, Universidade Federal de Minas Gerais, Brasil. ORCID https://orcid.org/0000-0003-0831-148X. E-mail: ivanaparrela@ufmg.br 


\section{INTRODUÇÃO}

"Avaliação de documentos" é um tema de suma importância para a Arquivística, tanto por ressaltar seu papel estratégico na racionalização da produção documental como por tornar eficaz a gestão de documentos, quanto para a garantia dos valores secundários dos documentos.

Várias discussões, de ordem teórica, prática e metodológica, vêm sendo produzidas em diferentes países, algumas com mais proximidade com a realidade brasileira.

País de tradição histórica na área de Arquivos, a Alemanha contribui de maneira notável em matéria de avaliação. Todavia, a literatura que produz em outros idiomas sobre a teoria e prática de sua Arquivologia limita-se à tradução de poucos artigos para o inglês, o que se torna um fator limitador de estudos para outros países.

Este artigo constitui um dos produtos de um intercâmbio realizado naquele país, assim como parte de um estudo de doutorado Integra um projeto que tem como um de seus objetivos analisar a questão da avaliação de documentos, com apoio em uma abordagem epistemológica, envolvendo discussões em países importantes no estudo da Arquivística, como a Alemanha. 0 contato mais próximo faz 0 olhar ficar mais atento às especificidades culturais ou aquelas de ordem prática. Pretende-se com este artigo discorrer sobre a avaliação de documentos na Alemanha, especificamente no âmbito dos Arquivos Federais (Bundesarchiv).

A importância deste trabalho justifica-se por ampliar as informações arquivísticas de um país com uma rica produção sobre arquivos, porém pouco difundida fora dele. Caracteriza por ser qualitativa e de caráter exploratório. A metodologia utilizada contemplou a pesquisa bibliográfica e a entrevista estruturada foi usada como técnica de coleta de dados.

Os Arquivos Nacionais exerceram, e continuam a exercer, importante papel para a história e a identidade nacional de um país. Historicamente, conforme Berger (2012), foram importantes para legitimar os Estados-Nação e os Impérios. Sua existência como repositórios institucionalizados dos registros sobre o passado nacional está invariavelmente ligada ao que produz o Estado-Nação moderno e à sutileza dos arquivos produzidos no presente, que devem ser cuidadosamente observados, para que possam se tornar o passado em um futuro próximo.

Silva (2019) discorre que no topo do sistema de arquivos alemão estão os Arquivos Federais, cuja tarefa principal é assegurar a confiabilidade do material arquivístico do Governo Federal e torná-Io acessível ao público interessado. 


\section{A TEORIA DE AVALIAÇÃO DE DOCUMENTOS NA ALEMANHA}

A Alemanha, que se tornou conhecida pela grande tradição de racionalização de suas atividades administrativas e pelo fortalecimento de um método de escrita da história baseado na crítica documental, no século XIX³, foi um dos primeiros países a se preocupar com a avaliação de documentos.

Segundo Couture (2003), enquanto, pelo menos no início, a Inglaterra avaliava para eliminar, a Alemanha fazia isso para conservar.

Com Karl Otto Müller, a partir de 1928, Heinrich Otto Meisner, em 1937, e George Wilhelm-Sante e Wilhelm Rhor, em 1957, a importância do organismo criador foi o primeiro ponto de reflexão a ser explorado pelos arquivistas alemães em matéria de avaliação. Fritz W. Zimmerman, desde o final dos anos 50 até 0 final dos anos 70, e Arthur Zeche, em 1965, se interessam, cada qual a sua maneira, pelo uso dos documentos. Ao responder como arquivista da Alemanha oriental, Joachim Schreckenbach, Hans Booms (1972 e 1987) defendia que 0 arquivo deveria dar testemunho de todas as atividades ao conjunto da sociedade. A importância do organismo criador, o uso dos documentos e a aproximação social são as principais vias que têm destacado os arquivistas alemães quando se trata de avaliação (COUTURE, 2003, p. 26, tradução nossa).

Arquivista alemão respeitado, que trabalhou nos Arquivos Federais em 1955, Hans Booms declarou que a teoria de arquivo estava desatualizada à época do pós-guerra, e por isso precisava de uma nova abordagem para à ciência arquivística alemã, mais consistente com os princípios democráticos recém-introduzidos, com base nos quais a República Federal Alemã foi fundada.

Segundo Kenosi e Moatlhodi (2012), a abordagem de Booms sugere que produtores, usuários e custodiadores de documentos devem trabalhar juntos, para definir e assumir a responsabilidade de documentar um setor específico da sociedade, o "universo documentário" de uma organização, grupo ou atividade específica. 0 argumento central de Booms apoiava-se no fato de que a sociedade, em vez de pesquisadores em potencial ou de administradores atuais, gera os valores que definem 0 significado, ou valor arquivístico, dos registros que cria (Booms, 1987, p. 69). Por isso, sua ideologia de avaliação chamou-se "modelo social".

Booms difere de Schellenberg ao sugerir que os arquivistas tinham poder absoluto na seleção dos registros permanentes, prevendo futuras necessidades de pesquisa. [...] Para tomar decisões de avaliação, afirma Booms, 0 arquivista deve trabalhar a partir de um conhecimento da estrutura social e dos valores dos registros contemporâneos [...]. Ele ressalta que os arquivistas devem identificar os valores de uma sociedade examinando as funções dos próprios produtores de documentos e o relacionamento entre essas funções e os registros criados (KENOSI, MOATLHODI, 2012, p. 30, tradução nossa).

3 Hoje, a exigência de trabalhar com fontes documentais da época analisada já se tornou um aspecto constituinte da metodologia de pesquisa da História. Isso faz com que nos esqueçamos, nas análises da Arquivologia, da importância dos chamados "historicistas alemães", como Leopold von Ranke, como propositores de uma crítica documental rigorosa, para a produção historiográfica, que produzisse não apenas "escrevendo histórias a partir de outras histórias" (GAY, 1990, p. 76). Tal postura contribuiu enormemente para a organização e difusão de conjuntos documentais das instituições arquivísticas em periódicos e nas coleções monumentais (PARRELA, 2013). 
Para o pensador, é a sociedade, a partir da qual os registros foram produzidos, que fornecerá os subsídios ao arquivista para avaliar, pois é para ela (sociedade) que os documentos serão preservados e consultados. No entanto, a abordagem de Booms, baseada em "futurologia arquivística", mostrou-se impossível de ser praticada.

Importante lembrar que a Alemanha foi um dos primeiros países a adotar o princípio da proveniência, um dos mais importantes da Arquivística, o qual prega que 0 arquivo produzido por uma entidade coletiva, pessoa ou família não deve ser misturado aos de outras entidades produtoras (DICIONÁRIO DE TERMINOLOGIA ARQUIVÍSTICA, 2005).

A esse respeito, discorre Bruebach (2003, p. 383, tradução nossa):

[...] antes de o princípio da proveniência ganhar suas explicações teóricas, por intermédio de Muller, Feith e Fruin, na Holanda já era seguido no dia a dia de trabalho por arquivistas na França (desde a década de 1840) e Alemanha (desde a década de 1880). A razão de esses três países pela primeira vez pensarem nas dimensões de "respeito aos fundos" e ordem original é bastante simples: foram eles, juntamente com a Itália, reorganizados em suas administrações durante a era napoleônica. [...]

Desde os anos 1990, após a reunificação alemã, o debate sobre a ciência dos arquivos concentrase principalmente em três campos de interesse: avaliação, arquivamento de documentos eletrônicos e descrição e acesso.

Bruebach (2003) destaca que desde o início das discussões sobre avaliação (1905) até 0 início dos anos 1990 havia dois polos de debate: a avaliação baseada em função versus avalição baseada em conteúdo. Segundo o autor, já em 1936 os primeiros pensamentos sobre uma política de avaliação e a transparência de decisões de avaliação foram retomados.

Heinrich-Otto Meisner inventou o que chamou de "Motivenberichte". Os arquivistas tiveram que relatar suas decisões de avaliação, suas estratégias e suas motivações para a transferência de registros dos arquivos do estado da Prússia. 0 objetivo era obter uma avaliação geral estratégica obrigatória, a ser aplicada a todos os arquivos do Estado prussiano, com base em uma análise funcional minuciosa e detalhada de todas as agências e nas estratégias de administração e avaliação especiais aplicáveis a um grupo de criadores de registros e/ou grupos de registros. A abordagem schellenberguiana também teve influência na década de 1950, inclusive nas ideias de Meisner, constituindo-se na nova tradução das diretrizes que Schellenberg escreveu para o pessoal do The National Archives and Records Administration (NARA), apresentada por Angelika Menne-Haritz, em 1991, principalmente por razões de ensino, a qual impulsionou novas discussões. 
Para Menne-Haritz (1994), Meisner e outros teóricos da década de 1930 não exerceram influência nos cinquenta anos subsequentes de debate sobre avaliação na Alemanha, rejeitando abordagens para avaliação (e, em alguns casos, até para descrição) com base no princípio da proveniência e categorizandoas como pertencentes ao século XIX. No pós-guerra, a Alemanha não reconheceu em seus arquivos desenvolvimentos ocorridos no exterior, como a abordagem de Schellenberg. Para a autora, Bodo Uhl explica esse fenômeno apontando que os arquivistas alemães eram, antes de tudo, historiadores e, portanto, estavam muito concentrados no conteúdo das fontes para perceber a aplicabilidade do conceito de Schellenberg.

Em seu artigo The German appraisal discussion since 1990: an overview, Isabel Taylor destaca que o desenvolvimento da teoria de avaliação de arquivos alemã desde 1990 tem sido pouco discutido no mundo de língua inglesa. De modo geral, o texto revela uma visão introdutória do modelo federführungs, desenvolvido pelo Bundesarchiv (Arquivos Federais), abordagem de avaliação vertical e horizontal do Landesarchiv (Aquivos do Estado) Baden-Württemberg e os planos de documentação típicos de arquivos municipais e universitários.

Taylor (2016) relata que as discussões na Alemanha se concentravam tanto nas abordagens estrangeiras, por meio da mediação de Menne-Haritz dos conceitos schellenberguianos, quanto na estratégia de documentação americana, defendida por Helen Samuels; na estratégia holandesa PIVOT4; ou, ainda, na ideia do arquivo intermediário pioneiro da NARA e da abordagem de macroavaliação, do canadense Terry Cook, e nas domésticas, concentrando-se apenas nos modelos e tendências alemãs.

Contudo, a influência de Bodo Uhl no debate de avaliação nos últimos 25 anos também tem sido altamente significativa. Em um artigo baseado em sua apresentação no $50^{\circ}$ Sudwestdeutscher Archivtag em Biberach an der Riß, em 1990, após um resumo crítico da discussão anterior sobre avaliação, ele argumenta contra a tentativa de encontrar uma teoria final do valor do arquivo que seria aplicável a todas as agências, tipos de arquivos e situações, pois isso exigiria como pré-requisito uma teoria do valor universalmente vinculativa ou reconhecida, que seria inimaginável em uma sociedade pluralista. Em vez disso, [propunha que] o foco deveria mudar para a eliminação da redundância, através de cooperação com outros arquivos. Uhl também pediu que os arquivistas evitassem qualquer avaliação que privilegiasse os interesses de pesquisa de qualquer grupo de estudiosos em particular, outra afirmação muito citada na literatura subsequente (TAYLOR, 2016, p. 15, tradução nossa).

4 "Projeto do Arquivo Nacional dos Países Baixos para avaliar as funções governamentais, em vez dos documentos individuais. Em vez de observar os tradicionais princípios de gestão de arquivos e documentos, que na verdade tendem, sobretudo, a selecionar e armazenar a informação gerada pelos processos administrativos, a estratégia proposta baseia a avaliação da informação no papel que esta representa nas atividades e tarefas governamentais" (COOK, 2018, p. 43). 
Uma característica notável do debate tem sido a maneira como esses modelos diferenciam-se de acordo com o tipo de arquivo; ou seja, com base no nível de governo (federal, estadual ou municipal) do qual 0 arquivo faz parte.

0 federführungsmodell é o modelo de avaliação dos Arquivos Federais. Baseia-se em tarefas, na diferenciação entre responsabilidade administrativa, ou primária (federführung), "envolvimento qualificado" e "envolvimento". Ser simples é a chave.

Embora diferentes posições administrativas estejam envolvidas de forma colaborativa no processo de tomada de decisão, a decisão final é de uma unidade organizacional especial, que é obrigada a realizar a liderança administrativa (federführung), a qual, geralmente, vai estar no topo da hierarquia administrativa, ou organograma. É importante observar que a determinação formal da responsabilidade administrativa principal (envolvimento qualificado) não estabelece, por si só, a destinação final dos registros. Isto é, não dispara automaticamente a necessidade de transferir os documentos correspondentes do cumprimento da tarefa ao arquivo, porque o próprio arquivista é quem tem a decisão da questão final sobre o significado do cumprimento da decisão. Portanto, mesmo que o federführung inequívoco esteja presente, a tarefa representada nos registros ainda pode ser avaliada como tão insignificante que eles devem ser destruídos (“envolvimento" simples). É, portanto, um processo de duas partes: o federführung é estabelecido; e a importância das tarefas capturadas nos registros é avaliada.

Para realizar a avaliação, existem alguns instrumentos de suporte aos arquivistas, como a matriz de avaliação de documentos governamentais, com alguns critérios de análise: significado da tarefa/ objetivo, jurisdição/legislação, tipo e qualidade da execução da tarefa, tradição e procedimentos para categorizar a área subordinada. Com base em critérios, perguntas são feitas para uma avaliação baseada também em pontos fortes e fracos. Há também o plano de arquivo como instrumento para a avaliação.

0 modelo de avaliação horizontal e vertical é o principal em nível estadual (Landesarchiv BadenWurttemberg). Seu objetivo é conseguir uma transferência de arquivos condensada, que, de forma confiável, reflita a seção das realidades da vida com a qual a tarefa de uma agência governamental está relacionada. Os arquivistas só podem conseguir isso se tiverem um conhecimento preciso dos processos realizados pela administração. A diferença fundamental entre o modelo de federführung e a avaliação horizontal e vertical é que, enquanto o primeiro se concentra na liderança administrativa, a última baseia-se no reconhecimento de que no serviço público estadual várias agências, geralmente, estão envolvidas no cumprimento de uma tarefa de ordem pública e os documentos mais informativos podem não ser necessariamente encontrados no nível mais alto. 
Taylor afirma que, apesar da falta de sucesso de Hans Booms em convencer o mundo arquivístico da utilidade mais ampla de perfis de documentação, eles já são de fato usados para avaliação em arquivos em nível municipal na Alemanha (para o qual um modelo importante foi desenvolvido em 2009) e em instituições de ensino superior (que correspondem ao foco de outros modelos ou tipos de documentos). Segundo ela, no início do desenvolvimento desta abordagem por parte dos arquivos municipais, a influência de Peter K. Weber foi crucial, enquanto Becker foi quem desenvolveu uma abordagem concreta para implementar perfis de documentação nos municípios. Becker explica seu uso em detalhes: a representação arquivística no nível municipal tem a missão de representar de maneira abrangente a sociedade local e as realidades de vida, documentar seus eventos, fenômenos e estruturas, grandes ou pequenas, e, assim, fazer justiça à pluralidade local (política, econômica, cultural e social).

No período após 1990, os modelos de avaliação alemães tornaram-se mais práticos, esquemáticos e sofisticados. Elementos de práticas de avaliação anteriores foram integrados em modelos, dos quais o mais complexo foi o de avaliação horizontal e vertical, desenvolvido pelo Landesarchiv Baden-Württemberg. Havia, agora, distinções claras entre diferentes escolas de pensamento, cada uma focada em um setor específico (federal, estadual ou municipal) no mundo arquivístico alemão, e 0 debate de avaliação reacendeu-se de forma particularmente animada e prolífica. No entanto, o desenvolvimento de registros públicos cada vez mais caóticos após o advento da TI começou a apresentar novos desafios, que agora começam a ser endereçado. Um novo capítulo da discussão sobre avaliação alemã está começando, aqui novamente prefigurado por Uhl em 1990. (TAYLOR, 2016, p. 20, tradução nossa).

Assim as discussões teóricas sobre a complexidade prática dos documentos traduzem um campo fértil de debates, modelos sobre a avaliação de documentos na Alemanha, que poderiam ser mais amplos e difundidos no campo internacional.

\section{OS ARQUIVOS FEDERAIS ALEMÃES - METODOLOGIA E RESULTADOS}

0 caráter exploratório do artigo justifica-se por se tratar de uma pesquisa em andamento e pelo fato de 0 objeto em destaque neste trabalho - no caso, a avalição de documentos na Alemanha - ser um tema de suma importância, mas pouco difundido no Brasil, tornando-se um artefato promissor na discussão epistemológica que se pretende construir no decorrer do percurso de doutoramento.

A metodologia, apoiada em uma pesquisa bibliográfica, remete a artigos científicos sobre o objeto-tema, exposto no corpo do trabalho, e complementa a escolha técnica de coleta de dados por meio de entrevista ${ }^{5}$ estruturada realizada ao Arquivo Federal da Alemanha. A opção por esta instituição ocorreu por sua posição estratégica no cuidado ao patrimônio documental do país, função precípua de um arquivo nacional.

5 Em anexo, segue o formulário de perguntas estruturadas aplicadas. As respostas foram traduzidas e adaptadas para este trabalho. 
Os Arquivos Federais (Bundesarchiv) tornam acessível o material arquivístico do Governo Federal, conforme consta em sua página eletrônica:

\begin{abstract}
Os Arquivos Federais têm o mandato legal de garantir os arquivos do governo federal no longo prazo e disponibilizá-los para uso. Trata-se de documentos (incluindo arquivos, mapas, fotos, cartazes, filmes e gravações sonoras em formato analógico e digital) produzidos pelos serviços centrais do Sacro Império Romano (1495-1806), da Confederação Alemã (18151866), Reiches Alemão (1867 / 71- 1945), das Zonas de Ocupação (1945-1949), da República Democrática Alemã (1949-1990) e da República Federal da Alemanha (desde 1949). Os Arquivos Federais decidem se esses documentos são "dignos de preservação arquivística"; ou seja, se têm valor duradouro para a pesquisa e compreensão da história e do presente, para a proteção de interesses legítimos dos cidadãos ou para a legislação, administração e jurisdição (BUNDESARCHIV, 2018, tradução nossa).
\end{abstract}

Silva (2019) esclarece que no âmbito federal existe a Lei de Arquivos Federais, ou Bundesarchivgesetz (BArchG), de 10 de março de 2017, que disciplina sobre a utilização e proteção dos arquivos do Governo Federal. As situações arquivísticas no país são reguladas pelas leis de arquivo em âmbito tanto federal quanto dos estados, diferentemente.

Os Arquivos Federais assessoram as autoridades federais na administração de seus documentos, de acordo com $0 \S^{\circ}(10)$ da bundesarchivgesetz, e coletam produções escritas de pessoas importantes, documentos de partidos, associações de importância nacional e fontes jornalísticas.

No Brasil, a Lei 8.150/1991, ou “Lei de Arquivos", dispõe sobre a política nacional de arquivos públicos e privados. Ela confere ao Poder Público o dever de zelar pela gestão documental e pela proteção especial a documentos de arquivo (art. $1^{\circ}$ ) produzidos e recebidos por órgãos públicos, instituições de caráter público e entidades privadas. Em seu art. 12, prescreve que os arquivos privados podem ser identificados pelo Poder Público como de interesse público e social, desde que sejam considerados como conjuntos de fontes relevantes para a história e o desenvolvimento científico nacional.

Importante ressaltar uma diferença entre as duas leis: a lei de arquivos brasileira se aplica ao Poder Público, ou seja, aos órgãos das esferas federal, estadual e municipal, ao passo que a bundesarchivgesetz se refere apenas ao âmbito federal do governo, cumprindo a cada estado ter sua própria lei de arquivo.

Como autoridade federal superior, os Arquivos Federais fazem parte da área de negócios do ministro de Estado da Cultura na Chancelaria Federal, do comissário do governo federal para a cultura e dos meios de comunicação.

Pretendia-se que a aplicação da entrevista ocorresse in loco nos Arquivos Federais, com equipe técnica responsável pela implementação das ações de avalição dentro do órgão. 0 primeiro contato foi 
feito via página eletrônica ${ }^{6}$ da instituição, solicitando a entrevista e explicando o objetivo do trabalho, em meados de maio de 2019. Em 4 de junho, o Dr. Mirjam Sprau, consultor na Divisão GW 1 (Planejamento Estratégico, Apoio à Gestão, Questões de Política Arquivística) dos Arquivos Federais, manifestou, via correio eletrônico, que uma visita in loco seria impossível, por motivos institucionais (época de férias e vários profissionais envolvidos nas respostas a pesquisa), mas que a equipe responderia às questões postas por aquele canal. Em 3 de julho do mesmo ano, as questões foram respondidas pelo Dr. Mirjam Sprau, em nome da equipe do Bundersarchiv,

0 Departamento GW (Grundsatz und Wissenschaft) é responsável por questões de arquivo e assuntos científicos. Sua sede fica em Koblenz. Coordena questões técnicas abrangentes, como, criação de inventário, relações públicas, treinamento, relações internacionais e questões relacionadas à lei de arquivos, e apoia a Gerência no planejamento estratégico. Os departamentos responsáveis pelas edições científicas dos Arquivos Federais também estão resumidos no Departamento GW, ao qual também pertence o Memorial de Rastatt. $^{7}$

A análise de dados se deu mediante a transcrição do discurso do entrevistado, de maneira adaptada, e a análise qualitativa das informações. De início, ele já ressaltou a questão estrutural que rege as instituições arquivísticas públicas no país: "Os arquivos públicos na Alemanha são organizados de acordo com a estrutura do nosso país, divididos em nível municipal e estadual. 0 nível municipal inclui cidades, municípios e condados; o nível estadual é dividido em 16 estados ("Bundesländer") e 0 nível federal. De acordo com nossa constituição, cada nível tem suas próprias obrigações e responsabilidades e possui seus próprios arquivos. Os Arquivos Federais não são obrigados a implicar regulamentos ou estabelecer regras para estratégias de avaliação em outros arquivos. Portanto, vemonos em posição de responder suas perguntas apenas para os Arquivos Federais da Alemanha”.

0 entrevistado, indagado sobre a atuação do arquivista dentro das fases do ciclo de vida dos arquivos, respondeu: "Um arquivista dos Arquivos Federais atua principalmente no estágio intermediário e permanente do ciclo de vida de um documento. Um pequeno grupo de nossos arquivistas trabalha no campo da consultoria administrativa sobre o plano de arquivos/plano de armazenamento de registros, o processo de formação de um arquivo, o estabelecimento de datas de descarte e o descarte real em arquivos federais. Além desse pequeno campo, nossos arquivistas trabalham com registros cujo período

6 https://www.bundesarchiv.de/DE/Navigation/Meta/Kontakt/kontakt.html

7 Memorial da Liberdade na História Alemã, instituição museológica dedicada às diferentes lutas pela liberdade, pela democracia e pela unidade, de 1848 a 1990, conforme indica o site da instituição: https://www.bundesarchiv.de/erinnerungsstaette/. Acesso 15. Abril.2020. 
de retenção expirou. Alguns focam na avaliação (estágio intermediário) e descrição (permanente), outros na preservação e medidas tomadas para disponibilizar materiais de arquivo para acesso (estágio permanente)".

Questionado sobre como é o processo de avaliação e se eles utilizam algum instrumento, por exemplo, uma tabela de temporalidade, o entrevistado declarou: "Para os ministérios, é possível fazer a transferência dos conjuntos documentais para 0 arquivo intermediário dos Arquivos Federais. A avaliação começa a ser feita, e a experiência mostra que esses serviços intermediários de arquivos suportam com êxito a obrigação legal de transferir registros dos ministérios alemães para os Arquivos Federais, bem como o processo de avaliação, fornecendo uma visão dos registros de vários ministérios referentes ao mesmo período de tempo. 0 princípio principal para a avaliação dos registros do ministério é o chamado 'Federführungsprinzip' (princípio da responsabilidade primária). A tradição histórica mais valiosa é preservada através dos registros do ministério que recebeu a responsabilidade primária de uma certa lei ou projeto político do chanceler. Nesses registros, todas as colaborações de outros ministérios ou agências governamentais inferiores estão incluídas de maneira abrangente. Embora o "princípio da responsabilidade primária" seja um princípio significativo, nunca é realizado de maneira estritamente formal. Ele deve ser acompanhado pelo valor do conteúdo, representando as discussões políticas norteadoras nos ministérios federais, mostrando a existência de uma certa lei. Para a avaliação de registros do Bundeskanzleramt - chancelaria federal-, os registros do Bundeskanzleramt não estão vinculados a essas estratégias de avaliação. Como a estrutura do Bundeskanzleramt reflete a responsabilidade dos ministérios, o valor histórico dos registros é notavelmente alto. Portanto, a maior quantidade desses registros está sendo preservada. Para a avaliação de registros de agências governamentais inferiores, os registros das agências governamentais ficam sob a orientação de um ministério, responsável por executar, pesquisar ou colocar em ação as decisões políticas tomadas, as quais estão vinculadas ao 'princípio da responsabilidade primária' (após o ministério), bem como a outra avaliação estratégia, que inclui elementos da 'estratégia de cima para baixo' (preservação de registros no mais alto nível hierárquico). Como primeiro passo, as agências governamentais e sua responsabilidade estão sendo avaliadas e categorizadas de acordo com as seguintes perguntas: Cumprir o trabalho é uma rotina? Quão forte é a agência governamental vinculada à vigilância do ministério e/ ou sujeita a certas leis? Quanto é o trabalho da agência governamental representado nos registros do ministério orientador ("estratégia de cima para baixo"). Quão grande é o impacto que a agência governamental tem na vida de um cidadão (por exemplo, a polícia federal)? Quão grande é o impacto 
que uma agência governamental específica tem sobre o reflexo da política alemã em geral? Com que intensidade a agência governamental representa importantes discussões políticas na sociedade alemã? Junto a essas questões, a agência governamental é categorizada em três níveis, que representam três etapas de avaliação, desde preservar apenas uma pequena quantidade de representantes da agência governamental até preservar registros uniformes de determinadas divisões/unidades e, às vezes, arquivos de casos. Dois instrumentos apoiam o processo administrativo: informações sobre a organização e estrutura de uma agência governamental; e o plano de arquivo".

Os Arquivos Federais assumem total responsabilidade pela avaliação, juntamente com 0 órgão governamental relacionado, e pelo apoio ao processo de avaliação, conforme $0 \S 3^{\circ}$ do BArchG (Bundesarchivgesetz, ou Lei dos arquivos federais, " $\$ 3^{\circ}$ - Tarefas dos Arquivos Federais). A missão dos Arquivos Federais consiste em assegurar, utilizar e explorar cientificamente os arquivos da Federação no longo prazo e garantir o acesso a eles, protegendo, ao mesmo tempo, os interesses privados ou públicos. Isso também pode ser feito por intermédio da digitalização e acessibilidade pública na Internet. Os Arquivos Federais determinam o valor duradouro dos documentos em consulta com o organismo da oferta" (Bundesarchivgesetz, 2017, tradução nossa).

Sobre a influência de teóricos na avaliação, relatou-se que Booms exerceu grande impacto no trabalho deles como presidente dos Arquivos Federais. Na opinião do respondente, "Schellenberg foi 0 teórico mais importante para nossa avaliação de evidências e conteúdo".

Questionado sobre se 0 advento dos documentos digitais impactou os Arquivos Federais, o entrevistado afirmou: "A estratégia geral de avaliação dos Arquivos Federais não foi e não será alterada devido a uma mudança no meio dos registros. No entanto, a mudança digital tem um enorme impacto: criou a necessidade de avaliação de novas formas de registros (por exemplo, procedimentos relacionados a casos), bem como uma nova estratégia de preservação para registros nascidos digitais. Nosso chamado ‘depósito digital' contém registros nato-digitais e digitalizados (arquivos, fotos, mapas etc.)".

\section{CONSIDERAÇÕES FINAIS}

A oportunidade de observar e estudar mais de perto o funcionamento de um sistema de arquivos e de uma instituição arquivística importante de um país como a Alemanha agregou muito à pesquisa de doutorado ora em curso. 
0 contexto histórico alemão da Arquivística, com suas leis e práticas levantadas, permite compreender uma lógica específica dos Arquivos Federais no processo de avaliação, que se difere da prática das outras esferas governamentais dentro do país. No modelo Federführungsprinzip, a análise estrutural “top down" é perceptível: a avaliação dos documentos do órgão que está no topo da estrutura/ organograma vai precedendo em relação aos documentos das agências subordinadas, com base em critérios e graus de importância das tarefas do que será "digno de arquivo". Essa análise confere ao arquivista um poder discricionário de decisão, na medida em que utiliza alguns instrumentos de referência, como, o plano de arquivos e a matriz de avaliação de documentos governamentais.

Esta foi apenas uma parada para a difusão de resultados no longo percurso metodológico rumo ao aprofundamento teórico e epistemológico que se pretende desenvolver na pesquisa no campo da avalição de documentos. A identificação dos distintivos da experiência alemã demonstra a necessidade de estudar os contextos históricos de organização do Estado e construção de políticas públicas de arquivo.

Apurou-se que os indícios levantados na Alemanha, com base em diferentes abordagens e em diferentes contextos, revelaram, mais uma vez que, estudar e, mais ainda, realizar a função avaliação não é uma tarefa simples de se pensar, muito menos de se praticar. É árdua, complexa e dificultosa, ainda mais quando se considera a grande produção dos documentos em órgãos e agências de um país. Todavia, é fundamental conhecer e debater com outras discussões tanto em diferentes níveis estruturais/organizacionais como em função dos diferentes contextos históricos.

Faz parte do crescimento hermenêutico enfrentar os desafios, colocar à prova os debates e continuar a percorrer o caminho árduo, em busca de respostas que a área nos coloca em questões práticas e reais. Ainda mais proeminente é que a Arquivística convirja mais para os debates e os caminhos entre os países, não para ter uma solução única, mas para que a troca de conhecimento engrandeça e fortaleça essa disciplina científica. Isso é fundamental e necessário em uma área do conhecimento.

\section{REFERÊNCIAS}

BERGER, Stefan. The role of national archives in constructing national master narratives in Europe. Archival Science, v. 13, p.1-22, 2013. D0I 10.1007/s10502-012-9188-z.

B00MS, Hans. Society and the formation of a documentary heritage: Issues in the appraisal of archival sources. Archivaria, v. 24(2), p. 69-107, 1987. Retrieved from http://journals.sfu.ca/archivar/ index.php/archivaria/article/viewFile/11415/12357. 
BRASIL. Lei no 8.159 , de 8 de janeiro de 1991. Dispõe sobre a política de arquivos públicos e privados e dá outras providências. Diário Oficial da União, Brasília, 9 jan. 1991. Disponível em: http://www.planalto.gov.br/ccivil_03/LEIS/L8159.htm. Acesso em: 16 abr. 2020.

BRASIL. Arquivo Nacional. Dicionário brasileiro de terminologia arquivística. Rio de Janeiro: Arquivo Nacional, 2005a. Disponível em: http://www.arquivonacional.gov.br/images/pdf/Dicion_Term_ Arquiv.pdf. Acesso em: 23 mar. 2020.

BRUEBACH, Nils. Archival Science in Germany - Traditions, Developments and Perspectives. Archival Science, v.3, p.379-399, 2003. DOI https://doi.org/10.1007/s10502-004-3420-4.

BUNDESARCHIV (Deutschland). Aufgaben des Bundesarchivs. 2018. Disponível em: http://www. bundesarchiv.de/DE/Navigation/Meta/Ueber-uns/Aufgaben/aufgaben.html. Acesso em: 15 nov. 2018.

COOK, Terry. 0 passado é prólogo: uma história das ideias arquivísticas desde 1898 e a futura mudança de paradigma. In: HEYMANN, Luciana; NEDEL, Letícia (Org.). Pensar os arquivos: uma antologia. Rio de Janeiro, FGV Editora, p. 17-82, 2018.

COUTURE, Carol. La función valoración en la archivística contemporánea: una sinergia entre varias consideraciones complementarias. Tabula: Revista de Archivos de Castilha y Léon, n. 6, p.23-49, 2003.

DEUTSCHLAND. Bundesarchivgesetz (BArchG). Gesetz über die Nutzung und Sicherung von Archivgut des Bundes vom 10. März 2017 (BGBI. I S. 410). Disponível em: http://www.bundesarchiv. de/DE/Navigation/Meta/Ueberuns/Rechtsgrundlagen/Bundesarchivgesetz/bundesarchivgesetz.html. Acesso em: 13 set. 2018.

GAY, Peter. 0 Estilo na História. São Paulo: Companhia das Letras, 1990.

KENOSI, Lekoko; MOATLHODI, Trevor. The determination of value in archival science and the ever evolving theories of records selection. The Eastern Librarian, v. 23(1), p. 24-36, 2012, ISSN: 10213643.

MENNE-HARITZ, Angelika. Appraisal or Documentation: Can We Appraise Archives by Selecting Content? American Archivist, v. 57, p.528-542, 1994.

PARRELA, Ivana Denise. Coleções e publicações documentais no Brasil: estratégias e temporalidades - 1930-1990. In: DUTRA, Eliana de Freitas (Org.). 0 Brasil em dois tempos: história, pensamento social e tempo presente. Belo Horizonte: Autêntica Editora, p. 91-108, 2013.

SILVA, Maria Juliana Nunes da. Relato de experiência em um arquivo na Alemanha. ÁGORA, ISSN 0103-3557, Florianópolis, v. 29, n. 59, p.1-12, jan./jun., 2019.

TAYLOR, Isabel. The German appraisal discussion since 1990: na Overview. Archives and Manuscripts, v.44, n.1, p.14-23, 2016 DOI: 10.1080/01576895.2015.1136226. 


\section{ANEXO I}

\section{Formulário aplicado na pesquisa ${ }^{8}$}

\section{INSTITUIÇÃO:}

\section{NOME: \\ CARGO/FUNÇÃO:}

1) Em geral, em diferentes países, existem diferenças em relação ao desempenho do arquivista no gerenciamento de registros / arquivos históricos. Como você observa que os arquivistas da Alemanha agem / trabalham? Você considera que 0 arquivista age principalmente em que estágio do ciclo de vida dos documentos de arquivo (atual, intermediário, permanente)?

2) Em que estágio do ciclo de vida do documento, o processo de avaliação do documento é realizado? Por favor, informe os detalhes sobre o procedimento para eliminação do documento e sobre a escolha para preservação do documento)?

3) Em termos gerais, você poderia fornecer algumas informações sobre como a avaliação do documento é realizada em instituições públicas federais? Por exemplo, existe algum instrumento de orientação, normas, leis? No Brasil, temos um instrumento chamado tabela de temporalidade. Este documento foi preparado e organizado pelo Conselho Nacional de Arquivos, para uso por órgãos públicos, que é o principal instrumento de avaliação. É possível encontrar algo semelhante na Alemanha?

4) Qual instituição é responsável por padronizar, monitorar e / ou aprovar as ações de avaliação dos documentos das instituições públicas federais?

5) Existem vários teóricos que discutiram a avaliação documental em Arquivologia (por exemplo: Schellemberg, Booms). Na Alemanha, houve alguma influência teórica na prática de avaliação de documentos? Houve influência de outros países em ações de avaliação?

6) Houve impacto / mudança nessa prática de arquivo com 0 advento de documentos digitais além da prática com documentos em papel? Se sim, como? E como o problema está sendo tratado na avaliação de documentos digitais?

7) Gostaria de comentar sobre outro tópico ainda não mencionado? Por exemplo, sugestão de fonte bibliográfica. Teremos o maior prazer em receber suas considerações finais e outros detalhes úteis para nossa pesquisa que você gostaria de compartilhar conosco.

8 Aplicado na versão em inglês. 